\title{
Ensino por investigação na visão de professores de Ciências em um contexto de formação continuada
}

\begin{abstract}
Joici de Carvalho Leite
Maria Aparecida Rodrigues

Carlos Alberto de Oliveira Magalhães Júnior

Resumo

Dentre as diversas razões que justificam a formação continuada de professores de Ciências, destacamos a necessidade de reflexões críticas sobre suas práticas, com vistas à melhoria da aprendizagem dos estudantes. Nesse sentido, discutimos, no presente trabalho, as compreensões de professores acerca do ensino por investigação, em um processo de formação continuada. Os dados foram coletados após a realização de um minicurso com duração de doze horas com professores de Ciências e Química, que iniciavam a participação em um grupo de estudos para aprofundar os conhecimentos do tema em questão. Participaram da pesquisa dez professores, que responderam duas questões abertas, versando sobre aspectos da prática docente e do ensino de Ciências por investigação. A análise de conteúdo das respostas revelou apropriação de elementos importantes inerentes ao ensino por investigação, entre eles, a mediação do professor, a resolução de problemas e a elaboração de hipóteses pelos alunos.

Palavras-chave: Ensino de Ciências, Ensino por investigação, Formação continuada.

\section{Abstract \\ Inquiry-based teaching in the vision of science teachers in a continuing education context}

Among the various reasons that justify the continuing education of science teachers, the necessity of critical reflections on their practices to improve student learning is emphasized. Thus, teacher understanding regarding inquiry-based teaching is discussed, in the present study, in a continuing education process. The data were collected after a 12-hour minicourse with science and chemistry teachers, who initiated participation in a study group to deepen the knowledge of the theme in question. Ten teachers, who responded to two open questions, discussing aspects of teacher practices and inquiry-based science teaching, participated in the research. Content analysis of the responses revealed appropriation of important elements inherent to inquiry-based teaching (e.g. teacher mediation, problem solving and student hypothesis formulation).
\end{abstract}

Keywords: science teaching, inquiry-based teaching, continuing education. 


\title{
Introdução
}

\section{Ensino de Ciências}

As aulas de Ciências podem ser espaços propícios para promover diversas interações educativas, pois essa disciplina debate diversos temas que possibilitam expressar ideias, sentimentos e conhecimentos científicos. Silva $(1996$, p. 46) diz que o ensino de Ciências tem por objetivo:

\begin{abstract}
"[...] formar um indivíduo que saiba buscar o conhecimento, que tenha motivação para continuar aprendendo por si, participe ativamente de sua comunidade e contribua para o seu desenvolvimento: que seja capaz de questionar, refletir e raciocinar (seja alguém que pensa), e seja capaz de buscar soluções para problemas cotidianos, saiba comunicar-se e relacionar-se sadiamente com as pessoas e que tenha respeito pela vida e pela natureza."
\end{abstract}

Concordamos com Silva que o aluno não pode ser um agente passivo no seu contexto social, e que o ensino de Ciências pode proporcionar competências e habilidades para que cada indivíduo venha a interagir com o mundo que o cerca e também interpretá-lo.

O ensino de Ciências no Brasil começou a ser implementado no currículo do ensino básico a partir da década de 1950. Isto aconteceu para acompanhar todo o desenvolvimento industrial e tecnológico no qual o país estava adentrando, acompanhando os países desenvolvidos da época.

De acordo com Krasilchik (1987), o ensino de Ciências no Brasil foi promovido nas últimas décadas como uma "coleção de fatos". O aluno, para aprender Ciência, tinha que memorizar esses fatos, e não foi ensinado a eles o processo científico; já se mostravam diretamente os resultados.

Para Carvalho et al. (1998, p. 12), "o ensino somente se realiza e merece este nome se for eficaz, se fizer o aluno de fato aprender". O professor tem o dever de orientar o seu aluno no caminho da aprendizagem efetiva. A ação que o professor deve desenvolver durante as suas aulas deverá refletir na aprendizagem de seus alunos. Se isso não ocorrer, poderá haver um problema em algum percurso desse caminho.

Hoje não se aceita que seja repassado aos alunos uma ciência estanque, engessada. Busca-se um ensino que almeje a aculturação de conteúdos e não mais a acumulação. Os alunos devem ser orientados a construir o próprio conhecimento, já que ele é parte do processo de ensino e aprendizagem. "Propõe-se a ensinar Ciências a partir do ensino sobre Ciências" (CARVALHO et al., 2004, p. 3).

Nesta perspectiva, Bizzo (2002, p.14) afirma que

"O ensino de ciências deve proporcionar a todos os estudantes a oportunidade de desenvolver capacidades que neles despertem a inquietação diante do 
desconhecido, buscando explicações lógicas e razoáveis, amparadas em elementos tangíveis".

Os alunos têm, como parte fundamental de sua formação, o conhecimento científico, integrante do mundo moderno, destacando-se como parte essencial de conhecimentos necessários para o desenvolvimento das funções educativas no contexto escolar.

Uma ciência cidadã pode servir como instrumento favorável à socialização do saber em todas as classes sociais, na medida em que se refere à capacidade de problematização, de resolução de problemas, de transformação do homem e, por extensão, da sociedade.

\section{Ensino de Ciências por investigação}

Pautados em autores que discutem o ensino de Ciências (KRASILCHIK, 1987; CHASSOT, 1990; AZEVEDO, 2004; SÁ, 2009; CARVALHO, 2013) e também em algumas vivências, acreditamos que, no ensino de Ciências, exista a necessidade de um pluralismo metodológico que considere a diversidade de recursos pedagógicos e tecnológicos. "Deve-se buscar cada vez mais o entendimento científico pelo entendimento da ação, afastando-se da concepção de Ciência como conhecimento racional, acabado e imutável" (CHASSOT, 1990, p. 67).

Dessa forma, vários estudos sobre diferentes práticas pedagógicas vêm sendo discutidos nas últimas décadas, dentre eles, destaca-se o uso do ensino por investigação, considerado indispensável por muitos professores para o bom desenvolvimento da aprendizagem de conhecimentos científicos.

De acordo com Deboer (2006) apud Sá (2009), os primeiros registros de ensino investigativo nas salas de aula datam do século XIX. Já a iniciação desse ensino no Brasil se deu com as teorias da educação progressiva de John Dewey, introduzidas pelo Manifesto dos Pioneiros de 1932, e com a fundamentação na pedagogia construtivista dos trabalhos do epistemólogo Jean Piaget, explorando o cognitivo das crianças, e no papel do ambiente social e no desenvolvimento do raciocínio, com o psicólogo Lev Vygotsky (BORGES, 2010).

Azevedo (2004, p.22) salienta que as aulas investigativas são uma forma de oportunizar o aluno a participar do processo de aprendizagem. O aluno precisa perceber que os conteúdos trabalhados em sala de aula são de suma importância para a sua vivência no mundo cotidiano.

"Utilizar atividades investigativas como ponto de partida para desenvolver a compreensão de conceitos é uma forma de levar o aluno a participar de seu processo de aprendizagem, sair de uma postura passiva e começar a perceber e agir sobre o seu objeto de estudo, relacionando o objeto com acontecimentos e buscando as causas dessa relação, procurando, portanto, uma explicação causal para o resultado de suas ações e/ou interações." 
Portanto, o professor, como mediador do ensino investigativo, deve promover diferentes estratégias investigativas em sua prática, pois cada turma apresenta situações diversas. E o professor precisa se preocupar tanto com questões conceituais quanto metodológicas.

\title{
3 Formação continuada de professores
}

A sala de aula deve ser um ambiente de interação entre alunos, e alunos e professores. 0 professor é incumbido de mediar a construção do conhecimento científico, possibilitando aos alunos tornarem-se protagonistas no processo de ensino e aprendizagem. No entanto, para que este processo ocorra de forma harmônica, é requerido do professor um conjunto de habilidades para conseguir organizar, planejar e executar as suas aulas.

Em uma pesquisa com professores de Ciências, Magalhães Júnior e Pietrocola (2011, p. 187) constataram que os professores participantes da pesquisa, mesmo praticando um ensino fragmentado, "conseguem contextualizar as Ciências naturais no dia-a-dia de seus alunos". Os autores argumentam que os professores precisam tomar consciência sobre a importância de se readaptar ao momento escolar. Daí, a relevância de uma formação continuada, além da graduação.

Durante um longo tempo, a formação inicial dos professores era considerada suficiente para permitir o seu exercício profissional, mas hoje essa realidade se tornou obsoleta. Nesse sentido, Couto (2005, p.14) enfatiza: “O professor é o elemento chave para dar corpo às reformas na escola, as quais têm como principal meta a formação de professores para preparar cidadãos aptos para conviver e trabalhar com a complexidade do cotidiano".

O profissional da educação, no próprio processo de atuar, necessita constantemente repensar seus saberes adquiridos durante a formação inicial, pela dinamicidade da evolução dos conhecimentos científicos e pelas transformações que ocorrem na sociedade. Assim, Azevedo (2008, p. 3) relata:

\begin{abstract}
"Esses profissionais são, em nosso entendimento, protagonistas desse complexo universo educacional. Sabemos, no entanto, que não são novas as tentativas de reflexão sobre a docência em Ciências, como não são poucas as iniciativas no campo da formação de professores. Porém, esses temas são por demais complexos para que as pesquisas deem conta do esgotamento das discussões. Os diversos programas educacionais que se tentam implantar nas redes oficiais demonstram o esforço em buscar sempre novas orientações que norteiem as práticas educativas nas salas de aula."
\end{abstract}

De acordo com Nóvoa (2009, p. 205), a educação passa por um momento de grandes incertezas, sente-se a necessidade urgente de mudanças significativas. São diversos os discursos 
sobre a formação continuada de professores, porém com pobreza de práticas. Dessa forma, ele argumenta que "É preciso fazer um esforço para manter a lucidez e, sobretudo, para construir propostas educativas que nos façam sair deste círculo vicioso e nos ajudem a definir o futuro da formação de professores".

As falhas na profissão docente não significam obstáculo intransponível, e os mais diversificados problemas podem ser resolvidos. Não existem propostas didáticas prontas e acabadas. Para tanto, os professores devem observar as próprias concepções e buscarem novas formas para a ampliação de suas perspectivas didáticas.

\section{Procedimentos Metodológicos}

Para o desenvolvimento deste estudo, buscaram-se os pressupostos da pesquisa qualitativa descrita por Minayo (1996). A autora define esse método como aquele que apresenta indagações subjetivas e no qual não há quantificação, pois se trabalha com um vasto universo de significados. Dessa forma, o significado e a intencionalidade são incorporados aos atos, às relações humanas e às estruturas sociais, possibilitando construções significativas de conhecimento.

A pesquisa foi realizada com dez professores que atuam nas disciplinas de Ciências e Química, da rede Estadual de Educação do Estado do Paraná, de acordo com as três etapas descritas a seguir:

i) Desenvolvimento de um minicurso: Com o intuito de constituir um grupo de estudos com professores de Ciências, foi oferecido a eles um minicurso com o tema "Abordagens de conteúdos de Química de forma Investigativa, nas aulas de Ciências". O minicurso ocorreu em três encontros de quatro horas no período de $23 / 10$ a 13/11/2013, totalizando 12 horas aulas. Esse minicurso contou com a participação de treze professores, os quais manifestaram interesse em fazer parte do grupo de estudos que seria formalizado posteriormente.

Durante o desenvolvimento do minicurso, foram abordados diversos temas, como, por exemplo: Introdução do ensino de Ciências no Brasil e como ele se encontra nos dias atuais; Conteúdos estruturantes das Diretrizes Curriculares de Ciências para a Educação Básica do Estado do Paraná (PARANÁ, 2008); Uma breve revisão histórica sobre o ensino por investigação que data do século XIX, e sua introdução no Brasil em meados da década de 1930; Apresentação de alguns exemplos de estratégias investigativas que poderiam ser usadas em sala de aula; A importância do professor como mediador do processo de ensino e aprendizagem; Necessidade de os professores proporem desafios aos seus alunos e instigá-los a resolverem problemas, a buscarem e quererem o conhecimento, a dialogarem sobre o conteúdo, pois só assim, eles passam de meros espectadores para sujeitos ativos da própria aprendizagem.

46 DOI: Em andamento.

R. Bras. de Ensino de C\&T 
ii) Resposta a um questionário: Após a realização do minicurso, foi formalizado o grupo de estudos, o qual iniciou suas atividades em março de 2014, com a participação de dez professores. Ressaltamos que, desses dez professores, seis eram oriundos do minicurso. Antes de dar início às atividades programadas para serem desenvolvidas no grupo, aplicou-se um questionário constituído das seguintes questões: 1. Para a elaboração do seu Plano de Trabalho Docente (PTD), quais referenciais teóricos você utiliza? 2. O que você entende por ensino de Ciências de forma investigativa? Em algum momento, você já contemplou esse tipo de ensino em sua prática? Faça um pequeno relato.

iii) Análise dos dados: As respostas dos questionários foram categorizadas, seguindo os pressupostos da análise de conteúdo de Bardin (2011).

\section{Resultados E Discussão}

A análise das respostas ao questionário se constituiu no estabelecimento de duas categorias, as quais se desdobraram em algumas subcategorias. A seguir, apresentamos a Tabela 1 , com todas as categorias encontradas, suas subcategorias e o número de unidades de análise que as compõem.

Tabela 1 - Categorias, Subcategorias e unidades de análise obtidas com as respostas dos professores

Categorias

Subcategorias unidades

de análise

\begin{tabular}{cll}
\hline $\begin{array}{c}\text { 1 Referenciais } \\
\text { que balizam o }\end{array}$ & 1.1 Livro didático (adotado pelo colégio) & 07 \\
trabalho docente & 1.2 Parâmetros Curriculares Nacionais (PCN) & 02 \\
& 1.3 Diretrizes Curriculares da Educação Básica (DCE) & 07 \\
& 1.4 Plano Político Pedagógico (PPP) & 04 \\
& 1.5 Livros didáticos diversos & 05 \\
& 1.6 Artigos & 03 \\
& 1.7 Revistas & 03 \\
2 Características & 2.1 Método de ensino & 02 \\
do ensino & 2.2 Resolução de problemas & 02 \\
investigativo & 2.3 Professor como mediador & 03 \\
\end{tabular}

R. B. E. C. T., vol 8, Ed. Sinect, jan-abr.2015 ISSN - 1982-873X

DOI: Em andamento. 
2.4 Questionamentos e diálogos entre os alunos

\section{Análise da categoria 1 - Referenciais que balizam o trabalho docente}

Com relação à primeira categoria que emergiu das respostas dos professores, constatamos que os referenciais mais destacados por eles na elaboração de planos de trabalhos docentes foram o PPP, DCE, livros didáticos adotados pelo colégio e livros didáticos diversos. Os fragmentos de respostas a seguir explicitam essas subcategorias:

"Para a elaboração do PTD costumo me deter primeiramente nas leis que norteiam a nossa prática pedagógica, [...] Diretrizes Curriculares e outros documentos de cunho oficial que possam ser relevantes. O Plano Político Pedagógico (PPP) da escola também é utilizado. Ademais, uso de livros, [...], livros didáticos e outros materiais que possam auxiliar nessa elaboração" (P3).

"Livro didático, Diretrizes Curriculares, Projeto Politico Pedagógico [...] Parâmetros Curriculares Nacionais e outros livros didáticos" (P5).

"[...] para realizar este trabalho escrever o PTD existe um documento orientador no Estado do Paraná que são as DCE que apresentam os conteúdos estruturantes da disciplina. Deve-se levar em conta também o PPP (Plano Político Pedagógico) da escola a qual esta inserido a partir desses documentos são feitas as consultas em livros didáticos" (P7).

De acordo com a Lei de Diretrizes e Bases da Educação Nacional (BRASIL, 1996), Lei de número 9.394 de 20 de Dezembro de 1996, Art. 13, os docentes incumbir-se-ão de: II - elaborar e cumprir plano de trabalho, segundo a proposta pedagógica do estabelecimento de ensino. Já nas Diretrizes Curriculares da Educação Básica - DCE (PARANÁ, 2008, p. 28), o PTD é assim definido:
"A partir da proposta pedagógica curricular, o professor elaborará seu plano de trabalho docente, documento de autoria, vinculado à realidade $e$ às necessidades de suas diferentes turmas e escolas de atuação. No plano, se explicitarão os conteúdos específicos a serem trabalhados nos bimestres, trimestres ou semestres letivos, bem como as especificações metodológicas que fundamentam a relação ensino/aprendizagem, além dos critérios $e$ instrumentos que objetivam a avaliação no cotidiano escolar." 
Segundo as DCE, com a organização do PTD, espera-se que o professor reflita sobre as abordagens e relações entre os conteúdos estruturantes, básicos e específicos. Reflita, ainda, sobre as expectativas de aprendizagem, as estratégias, os recursos utilizados e os critérios de avaliação.

Outro documento oficial mencionado por apenas dois participantes foi o PCN (BRASIL, 1998), conforme retratam os fragmentos de respostas:

"Para a elaboração do PTD costumo me deter primeiramente nas leis que norteiam a nossa prática pedagógica [...] Diretrizes Curriculares Nacionais e outros documentos de cunho oficial que possam ser relevantes" (P3).

"[...] Parâmetros Curriculares Nacionais [...]" (P5).

Faz sentido o fato de as DCE terem se sobressaído nas respostas dos pesquisados, tendo em vista que o Estado do Paraná dá muita ênfase a esse documento no ensino. Em contrapartida, abole os PCN, fazendo uma crítica contundente a esses documentos, argumentando que são vazios em conteúdo. Acredita-se que muitas das críticas dirigidas aos PCN sejam equívocos cometidos por muitos professores, até pelo fato de não receberem uma preparação adequada para compreender e praticar os fundamentos teórico-metodológicos presentes nesse documento (LEITE, 2009).

Podemos perceber, nas respostas dos professores, a preocupação em seguir as recomendações dos documentos oficiais. Ressaltamos que, embora seja válido o professor levar em conta os pressupostos desses documentos, é necessário certo cuidado, para que não sejam tolhidas a autonomia e a liberdade pedagógica dos professores.

Os professores também citaram, como referenciais usados para a elaboração de seus PTD, artigos, revistas e vídeos, no entanto poucos citaram de quais fontes seriam extraídos esses referenciais, por exemplo:

"[...] revistas, vídeos [...]" (P1).

"Também procuro me referenciar em artigos referentes aos assuntos trabalhados, vídeos educacionais e revistas voltadas ao ensino de química" (P4).

"[...] Ciência Hoje (online), artigos referentes ao assunto, veja na sala de aula" (P5).

Os artigos podem enriquecer os PTD dos professores, pois trazem consigo ideias de autores diferenciados daqueles recomendados nos documentos oficiais. Dessa forma, fazem com que o professor possa se abrir a novos horizontes. Muitas escolas do Paraná são assinantes de revistas especializadas em educação, o que facilita o acesso de professores e alunos. Já o uso de vídeos, de acordo com Moran (1995), proporciona uma multilinguística e o conhecimento de 
variados códigos e significações. Assim, há de se ter parcimônia para utilizar vídeos como referenciais para balizar o trabalho docente. Ele não pode ser usado apenas como complementação da aula, ele deve ter um significado pedagógico de ensino.

\section{Análise da categoria 2 - Características do ensino investigativo}

Com relação a essa categoria, os dados obtidos na pesquisa demonstram que os professores percebem elementos importantes do ensino por investigação. Para conceituar, de uma forma geral, o ensino por investigação, nos baseamos em Zômpero e Laburú (2011, p. 68), que assim o definem: "A perspectiva do ensino com base na investigação possibilita o aprimoramento do raciocínio e das habilidades cognitivas dos alunos, e também a cooperação entre eles, além de possibilitar que compreendam a natureza do trabalho científico". E também em Azevedo (2004), que expõe que uma atividade investigativa não pode se reduzir a uma mera observação ou manipulação de dados, ela deve levar o aluno a refletir, a discutir, a explicar e a relatar seu trabalho aos colegas.

Reunimos alguns trechos os quais revelam que dois dos professores pesquisados entendem o ensino investigativo como método de ensino:

"Ensino por Investigação seria um método de ensino em que, primeiramente, desperta-se o agir e o pensar do aluno [...]" (P3).

"O ensino investigativo é uma metodologia de ensino que leva o aluno a pensar sobre o por que dos fatos [...]" (P5).

Interessante observar o entendimento desses professores, pois o ensino por investigação se trata realmente de uma estratégia metodológica ou abordagem didática. Atualmente, o ensino possui uma pluralidade metodológica significativa, o que é muito importante para que o professor possa articular suas aulas, de acordo com a realidade de seu público alvo. No ensino investigativo, o ator principal do processo é o aluno, que sempre monitorado pelo professor, constrói o próprio conhecimento.

Identificamos três dos pesquisados os quais afirmaram que os alunos, durante o processo investigativo, devem ser os responsáveis pela resolução de problemas propostos durante as aulas. Assim, tivemos as seguintes menções:

"De uma maneira mais clara, a partir da resolução de uma situação problema, ou mesmo na busca dessa solução o aluno é levado a pensar e a deixar no conteúdo dado às respostas das quais precisa" (P3).

"[...] capacidade de tomar decisões, de avaliar e de resolver problemas, apropriando-se de conceitos e teorias" (P9).

50 DOI: Em andamento.

R. Bras. de Ensino de C\&T 
Destacamos a coerência das ideias desses professores, pois no ensino investigativo, os alunos são os sujeitos na construção do conhecimento. E para que esse conhecimento seja formulado por eles, há a necessidade de questionamentos para que, através da dúvida, eles pesquisem, interajam entre si e com o professor (mediador), formulem hipóteses para que as perguntas possam ser respondidas. Carvalho (2013) salienta que o problema proposto pelo professor a seu aluno não pode ser um problema qualquer, precisa ser muito bem pensado e articulado, levando em conta a realidade social e os conhecimentos prévios desse aluno. É preciso despertar a curiosidade e o interesse do aluno, de forma que ele passe a ter uma interação dialógica com os seus colegas de classe e com o professor, propondo hipóteses que serão testadas por todos em busca do conhecimento. "Não importa a forma investigativa que venha a aparecer: o essencial é que haja um problema a ser resolvido; e as condições para resolvê-lo são muito importantes [...]" (SASSERON, 2013, p. 43).

Na subcategoria professor como mediador, aspecto importante do ensino investigativo, percebemos que os professores ainda demonstram certa resistência, o que é mencionado por apenas um dos professores, como podemos observar no excerto a seguir:

"Não é fácil trabalhar como mediador, manter o diálogo constante com os alunos, teorizar com os alunos, experimentar, agir, pois com a demanda atual de alunos vai muito além das possibilidades que o professor tem para trabalhar com os mesmos" (P7).

O professor mediador seria aquele que, de acordo com Praia et al. (2002, p. 136), é um elo entre os saberes dos alunos e o conhecimento científico, ajudando-os a construir um saber novo. "Trata-se de mudança de conceitos, de competências e atitudes e não de simples aquisição de conceitos."

Fica a cargo do professor saber elaborar a pergunta certa e ouvir seus alunos, compartilhando informações com eles. Sabemos que ouvir, para quem foi educado em uma mentalidade tradicional, é bem difícil, no entanto necessário. $\mathrm{O}$ aluno deve expressar a própria voz, suas opiniões, e não apenas aquilo que o professor deseja ouvir. Por isso, a necessidade de as aulas de Ciências conterem atividades problematizadoras; assim, os alunos procuram soluções, testam, levantam hipóteses, dialogam com seus pares e com o professor, registram suas experiências, construindo juntos o conhecimento (OLIVEIRA, 2013).

Os questionamentos ou os diálogos, que também podem ser chamados de interações discursivas, são de vital importância para o ensino investigativo, como dois professores relatam: "[...] norteados por questões que exigem dos alunos pensarem, discutirem [...]" (P4); "[...] promovendo assim o questionamento e a busca por respostas [...]" (P5).

Sasseron (2013) afirma que é através do debate que os conhecimentos científicos podem vir a ser formados. Em uma aula investigativa, todos os detalhes são importantes, pois eles 
podem dar condições reais para o desenvolvimento do trabalho. Daí, a importância de o professor dar liberdade ao seu aluno, para que ele fale o que pensa e o que entendeu, no entanto o professor deve conduzir a aula para que ela não saia do foco. Como lembra Sasseron, "[...] essas interações discursivas devem ser promovidas pelo professor e cuidados precisam ser tomados para que o debate não se transforme em uma aula banal" (SASSERON, 2013, p. 43).

Nas respostas dos professores, pode-se identificar a importância de se dar autonomia aos alunos no ensino investigativo, como segue no excerto a seguir: “[...] possibilitando o desenvolvimento da autonomia e da capacidade de tomar decisões [...]" (P9).

Carvalho et al. (1998, p. 29) salientam que "Criar alunos autônomos e que saibam pensar, tomar as próprias decisões e estudar sozinhos, é uma das metas do ensino". Segundo essa autora, deve-se dar autonomia aos alunos desde as primeiras séries. No entanto, autonomia não significa deixar que os alunos conduzam a aula; os alunos devem seguir as orientações do professor. Um professor que deixa os alunos à vontade está muito longe de alcançar um ensino de qualidade. $O$ professor deve propor regras, não de forma imposta e, sim, explicadas, conversadas; dessa forma, o aluno poderá criar a sua autonomia moral e regras de convivência (CARVALHO et al., 1998).

Observamos que uma quantidade expressiva de professores, ou seja, oito dos pesquisados, mencionaram a elaboração de hipóteses ou reelaboração de conceitos por meio do ensino investigativo. Isso pode ser observado nos fragmentos de respostas a seguir:

$$
\begin{aligned}
& \text { "[...] levantar suas hipóteses sobre os fatos ocorridos e ao mesmo tempo } \\
& \text { descobrindo os fatos" (P5). } \\
& \text { "[...] motivação para chegar ao conhecimento mais aprofundado e elaborado } \\
& \text { [...] um desafio de reelaborar seus conceitos" (P6). }
\end{aligned}
$$

Como se pode perceber, os professores P5 e P6 destacaram elementos fundamentais do ensino investigativo. Nesse processo, os alunos, de forma individual ou em grupos, são orientados a procurar explicações pertinentes para suas indagações, sem ficar esperando respostas prontas e acabadas. Nesse sentido, Pietrocola (2004, p. 130) discute a importância da imaginação e da curiosidade para as atividades em sala de aula, afirmando com propriedade:

\footnotetext{
"As atividades cientificas tornam-se interessantes e instigadoras quando são capazes de exercitar nossa curiosidade. Por meio da imaginação, o pensamento passa a apreender o desconhecido buscando uma explicação para os enigmas. A curiosidade serve de fio condutor para as atividades, que de outra forma passariam a ser burocráticas e exercidas com o propósito de cumprir obrigações."
}

Ressaltamos ainda que a maioria dos professores destacou em seus relatos, que, pelo menos em algumas situações de sala de aula, trabalharam de forma investigativa com seus alunos. A 
seguir, apresentamos três fragmentos de respostas para exemplificar as atividades investigativas desenvolvidas por oito dos dez participantes da pesquisa:

"Eu estou aplicando uma oficina sobre a queima de alimentos, no qual aborda um caráter investigativo e problematizador, que promove atividades como calculo do valor energético de alimentos, leitura e interpretação de rótulos, composição dos alimentos e seus benefícios (nutrientes)" (P4).

"Ao trabalhar as questões ambientais, solicitei que os alunos fotografassem locais próximo à sua casa onde havia descuido com a natureza. É claro, que não foi fácil achar lugar para isto. Revelamos as fotos e montamos um painel. A partir disso estudamos as condições em que estavam os ambientes naquele momento, sempre perguntando: Por que as pessoas produzem tanto lixo? Por que não há lixeiras na rua? Por que não há locais para descartes de móveis, eletrodomésticos etc? E o trabalho dos órgãos competentes? Discutimos as questões politicas, sociais e econômicas do meio ambiente" (P8).

"Um exemplo de trabalho foi a discussão sobre a concepção de meio ambiente e saneamento básico dos alunos, uma pesquisa de como era o bairro em que eles moravam e a cidade. Trouxemos documentos oficiais sobre o tema, vídeos trabalhando os conceitos e dados sobre as condições existente em nossa região, Estado e país. Alguns materiais com reportagens recentes $e$ as condições de saúde em decorrência do estado em que se encontram. Em paralelo, propunha aos alunos, questionamentos que fizesse refletir sobre os dados coletados, as informações trazidas e as condições vividas nos bairros, proximidades da escola e de como a mídia tratava tudo isto" (P6).

Esses resultados revelam que boa parte dos professores pesquisados consegue elaborar situações de aprendizagem que oportunizem a participação dos alunos no processo ensinoaprendizagem, uma das condições necessárias para o ensino investigativo. De acordo com Carvalho et al. (1998), é preciso que os professores "saibam" elaborar atividades que inovem o seu método de ensino. E assim, propiciar aos alunos o desenvolvimento de suas habilidades e competências.

\section{Considerações Finais}

Por meio da análise de conteúdo das respostas fornecidas pelos professores, podemos dizer que alguns dos professores pesquisados conseguem perceber a importância de aspectos fundamentais relacionados ao ensino por investigação, tais como: mediação do professor, proposição de problemas a serem resolvidos pelos alunos, elaboração de hipóteses, entre outros. E que parte desses professores elabora situações de aprendizagem que permitem a participação 
do aluno, favorecendo esse tipo de ensino. Por fim, destacamos que atividades como as desenvolvidas durante o minicurso, bem como as que estão em andamento no grupo de estudos em vigência, são de extrema relevância para a formação continuada dos professores participantes.

\section{Referências}

AZEVEDO, M. C. P. S. Ensino por investigação: problematizando as atividades em sala de aula. In: CARVALHO, A. M. P. (Org.). Ensino de ciências: unindo a pesquisa e a prática. São Paulo: Pioneira Thomson Learning, 2004. p. 19-33.

AZEVEDO, M. N. Pesquisa-ação e atividades investigativas na aprendizagem da docência em Ciências. 2008. 224 f. Dissertação (Mestrado) - Faculdade de Educação da Universidade de São Paulo, Universidade de São Paulo, São Paulo, 2008.

BARDIN, L. Análise de Conteúdo. Tradução Luís Antero Reto, Augusto Pinheiro. São Paulo: Edições 70, 2011.

BIZZO, N. Ciências: fácil ou difícil? 2. ed. São Paulo: Ática, 2002.

BRASIL. Lei de Diretrizes e bases da educação nacional. Lei no 9.394, de 20 de dezembro de 1996. Disponível em: < http://www.planalto.gov.br/ccivil_03/leis/I9394.htm>. Acesso em: 22 jul. 2014. - Secretaria da Educação Fundamental. Parâmetros Curriculares Nacionais: Ciências Naturais: terceiro e quarto ciclos do Ensino Fundamental. Brasília: MEC/SEF, 1998. 138 p. Disponível em: <http://portal.mec.gov.br/seb/arquivos/pdf/ciencias.pdf>. Acesso em: ago. 2013.

BORGES, R. C. P. Formação de formadores para o ensino de ciências baseado em investigação. 2010. 257 f. Tese (Doutorado) - Programa de Pós-Graduação em Educação: Ensino de Ciências e Matemática, Faculdade de Educação da Universidade de São Paulo, São Paulo, 2010.

CARVALHO. A. M. P et al. Ciências no ensino fundamental: o conhecimento físico. São Paulo: Scipione, 1998. Critérios estruturantes para o ensino de Ciências. In: (Org.). Ensino de Ciências: unindo a pesquisa e a prática. São Paulo: Pioneira Thomson Learning, 2004. p. 1-17. . O ensino de Ciências e a proposição de sequências de ensino investigativas. In:

(Org.). Ensino de ciências por investigação: condições para a implementação em sala de aula. São Paulo: Cengage Learning, 2013. p. 1-20.

CHASSOT, A.I. A Educação no Ensino de Química. Ijuí, Rio Grande do Sul: Unijuí, 1990.

COUTO, M. E. S. Aprendizagem da docência de professores em curso de formação continuada na modalidade a distância. In: VIII CONGRESSO ESTADUAL PAULISTA SOBRE FORMAÇÃO DE 
EDUCADORES, 2005, Águas de Lindóia. Anais ... Águas de Lindóia : Unesp - Universidade Estadual Paulista, 2005. p. 14-23. Disponível em: <file:///D:/Downloads/9eixo.pdf>. Acesso em : 15 set. 2014.

KRASILCHIK, M. O professor e o currículo das ciências. São Paulo: EPU/EDUSP, 1987.

LEITE, R. F. Concepções de professores de química do ensino médio sobre Educação Ambiental. 2009. 245 f. Dissertação (Mestrado) - Programa de Pós-Graduação em Educação para a Ciência e a Matemática, Universidade Estadual de Maringá, Maringá, 2009.

MAGALHÃES JÚNIOR, C. A. O.; PIETROCOLA, M. Atuação de professores formados em Licenciatura Plena em Ciência. Alexandria: Revista de Educação em Ciência e Tecnologia, Santa Catarina, v.4, n.1, p.175-198, maio 2011.

MINAYO, M. C. S. O desafio do conhecimento: pesquisa qualitativa em saúde. 4. ed. São Paulo: Hucitec-Abrasco, 1996.

MORAN. J. O Vídeo na Sala de Aula. Comunicação \& Educação. São Paulo, v.2, p. 27-35, jan./abr. 1995.

NÓVOA, A. Para una formación de profesores construída dentro de la profesión. Revista de Educación, Madrid, n. 350, p. 203-218. sep./dic. 2009. Disponível em: $<$ http://www.mecd.gob.es/revista-de-educacion/numeros-revista-educacion/numerosanteriores/2009/re350.html>. Acesso: 29 out. 2013.

OLIVEIRA, C. M. A. de. O que se fala se escreve nas aulas de Ciências? In: CARVALHO, A.M.P. (Org.). Ensino de ciências por investigação: condições para a implementação em sala de aula. São Paulo: Cengage Learning, 2013. p. 63-75.

PARANÁ. Diretrizes curriculares para a educação básica: Ciências. Secretaria de Estado da Educação do Paraná. Paraná, $2008 . \quad$ Disponível em: $<$ http://www.educadores.diaadia.pr.gov.br/arquivos/File/diretrizes/dce_cien.pdf $>$, Acesso em: ago. 2013.

PIETROCOLA, M. Curiosidade e Imaginação - os caminhos do conhecimento nas ciências, nas artes e no ensino. In: CARVALHO, A. M. P. (Org.). Ensino de ciências: unindo a pesquisa e a prática. São Paulo: Pioneira Thomson Learning, 2004. p.119-133.

PRAIA, J. F. et al. Problema, teoria e observação em ciência: Para uma reorientação epistemológica da Educação em Ciência. Revista Ciência \& Educação, Bauru, v.8, n. 1, p.127-145, 2002.

SÁ, E. F. Discursos de professores sobre ensino de Ciências por investigação. 2009. 202 f. Tese (Doutorado) - Programa de Pós-graduação em Educação da Universidade Federal de Minas Gerais - Universidade Federal de Minas Gerais, Belo Horizonte, 2009. 
SASSERON, L. H. Interações discursivas e investigação em sala de aula: o papel do professor. In: CARVALHO, A.M.P. (Org.). Ensino de ciências por investigação: condições para a implementação em sala de aula. São Paulo: Cengage Learning, 2013. p. 41-62.

SILVA, M. R. Alfabetização: pressupostos para a formação do professor. In: Silva, M. R. (Org.). Ciências: formação de professores e ensino nas séries iniciais. Toledo: T., v.5, 1996.

ZÔMPERO, A. F.; LABURÚ, C. E. Atividades investigativas no Ensino de Ciências: aspectos históricos e diferentes abordagens. Revista Ensaio, Belo Horizonte, v.13, n. 3, p. 67-80, set. /dez. 2011.

Joici de Carvalho Leite - Mestre em Ensino de Ciências pelo Programa de Pós-Graduação em Educação para a Ciência e a Matemática do Centro de Ciências Exatas da Universidade Estadual de Maringá - UEM. E-mail: joicicarvalho@hotmail.com

Maria Aparecida Rodrigues - Doutora em Ciências pela Universidade Estadual de Campinas UNICAMP. Professora do Programa de Pós-Graduação em Educação para a Ciência e a Matemática - PCM/UEM - do Centro de Ciências Exatas da Universidade Estadual de Maringá/PR. E-mail: aparecidar@gmail.com

Carlos Alberto de Oliveira Magalhães Júnior - Doutor em Ciências pela Universidade Estadual de Maringá. Professor adjunto do Departamento de Ciências e do programa de Pós-graduação em Educação para a Ciência e a Matemática da Universidade Estadual de Maringá. E-mail: juniormagalhaes@hotmail.com 